University of Louisville

ThinkIR: The University of Louisville's Institutional Repository

Electronic Theses and Dissertations

$5-2012$

\title{
The adytum.
}

Lexi Bass

University of Louisville

Follow this and additional works at: https://ir.library.louisville.edu/etd

\section{Recommended Citation}

Bass, Lexi, "The adytum." (2012). Electronic Theses and Dissertations. Paper 82.

https://doi.org/10.18297/etd/82

This Master's Thesis is brought to you for free and open access by ThinkIR: The University of Louisville's Institutional Repository. It has been accepted for inclusion in Electronic Theses and Dissertations by an authorized administrator of ThinkIR: The University of Louisville's Institutional Repository. This title appears here courtesy of the author, who has retained all other copyrights. For more information, please contact thinkir@louisville.edu. 


\title{
THE ADYTUM
}

\author{
By \\ Lexi Bass \\ B.A., University of Kentucky, 2004
}

\begin{abstract}
A Thesis
Submitted to the Faculty of the

College of Arts and Sciences at the University of Louisville

In Partial Fulfillment of the Requirements

For the Degree of
\end{abstract}

Master of Arts

Department of Fine Arts

University of Louisville

Louisville, KY

May 2012 
Copyright 2012

Lexi Bass 


\section{THE ADYTUM}

By

Lexi Bass

M.A., University of Louisville, 2012

A Thesis Approved on

April 10, 2012

By the following Thesis Committee:

Mary Carothers, Thesis Director

Gabrielle Mayer

Krzysztof Wolek 


\section{DEDICATION:}

This work is dedicated to the balancing act that keeps us human and animal. 


\section{ACKNOWLEDGEMENTS:}

I am no island and there are many who helped me achieve my goals. I would like to acknowledge them, chronologically. Thank you to my Mother, Valencia, who praises my irrational desire to give until there is nothing left of me. Thank you to my father, Rex who taught me wordplay, sarcasm, and French language at an early age as this is the basis for my love of the sounds we make and the systems with which we communicate. Thank you to my siblings, Brandon and Charity for their endless support, love, talent, stability and merriment. I love them more than I can say. Thank you to all those who me taught me difficult and bitter lessons about power, personality, and balance. Thank you to all those who ever gave me an opportunity. Thank you to my talented friend, Megh Zahrndt for her dedication and loyalty to my many projects and to me. Thank you to all of my teachers. Thank you to Ryan Rivard and Ron Schildknecht for teaching me video. Thank

you especially to my Mentor, Mary Carothers for being a model teacher in her encouragement and unrestrained devotion to her students and community. Thank you also to Gabrielle Mayer for being a model teacher in her deep, methodical, and disciplined approach. You are both greatly inspiring to me. Thank you to Dr. Krzysztof Wolek and to all my dear friends in the School of Music for encouraging me to make music and for countless hours spent discussing philosophy, culture, and aesthetics. Thank you to Nia Boyd in the Writing Center who helped me turn my collage-style writing into something more linear. And thank you to Joey Crane, who, for his numerous talents, relentless love, encouragement and friendship, deserves all the good things the world could offer. Thank you Joey, for everything you give. We are two of a kind. I love you. 


\section{ABSTRACT: \\ THE ADYTUM \\ Lexi Bass}

April 10, 2012

This thesis explores the history of human spirituality and its present ambiguous place in our modern secular world. Accompanying the written thesis is documentation of my creative work by the same title.

First I will describe spirituality as a fundamental aspect of the human animal as promoted by R. Joseph. I will follow human spirituality through the culture of organized religion and summon Nietzsche's The Gay Science to discuss shame, sexuality, and religion, moving on to The Birth of Tragedy to discuss the problem of spirituality in modernity.

Next I will discuss power through the language of morality. An analysis of the golden rule will break down the language of love, self, and other. I will address morality as a method of manipulating power, and the delusions of idealism. I will discuss science as mythology that parades as detached logic. Concluding, I will suggest the importance of mythology to human spirituality and where modern people search for it in society.

Finally, I will express my intentions with my installation, The Adytum. I will describe the ways in which art and entertainment spaces are a modern sanctuary for spiritual introspection. I will discuss the roles of artists as they pertain to Nietzsche's three cultures and how Western culture enforces the role of artists as social change 
catalysts. I suggest how Westerners are encouraged to regard art and myth at a lower value with relation to science and the idealistic arrogance that occurs when society favors objective scientific understanding at the cost of losing all value in subjective experiential understanding. Ultimately I suggest the need for balancing our methods of understanding to maintain human spirituality. 
TABLE OF CONTENTS

PAGE

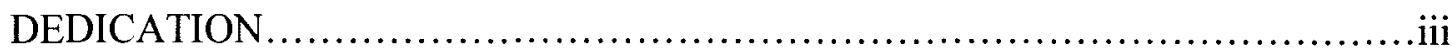

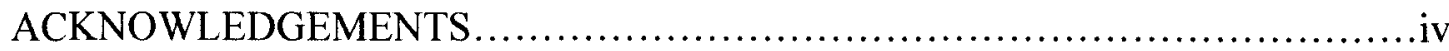

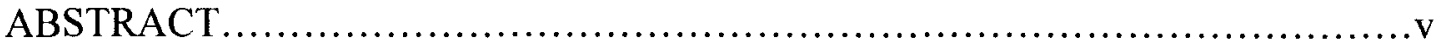

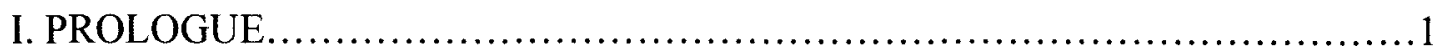

II. WHAT IS THE ROLE OF THE ARTIST?................................

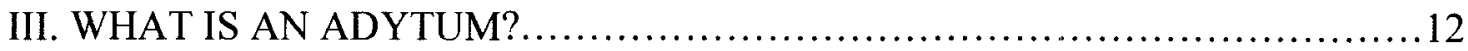

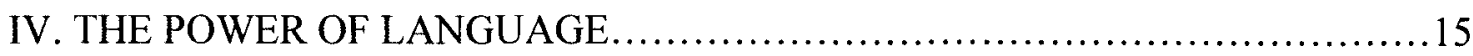

V. ON LOVE, SELF, AND OTHERS...............................................17

VI. ON SCIENCE AND CLASSIFICATION .......................................22

VII. THE DEATH OF MYTHOLOGY AND THE REBIRTH OF ART ...............25

VIII. THE ADYTUM: AN ARTIST'S STATEMENT ................................27

IX. THE MTYHOLOGY OF THE ADYTUM.......................................32

X. THE PURPOSE OF THE LANGUAGE IN THE ADYTUM.......................36

XI. THE IMAGERY OF THE ADYTUM ...................................... 38

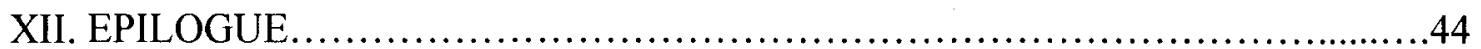

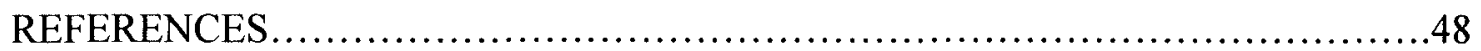

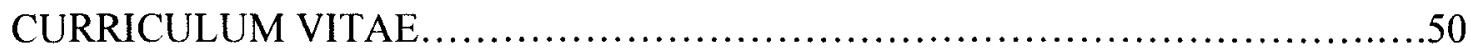




\section{PROLOGUE}

In 2002 I was date raped. This event although often indirectly, effects all of my work. While the experience itself was always describable by this one word, the physical, perceptual and circumstantial changes that followed the event could not be so neatly packaged with one economical phrase or word. I am constantly reassessing the impact of this experience and its complicated aftermath. For the past ten years, I have taken a direct approach in exploring this and other darkly complicated phenomena through personality, psychology, philosophy, spirituality and aesthetics. Though for a long time, my response to the memory of this event was resentful and bitter, by learning how to look at it from a more detached or naturalistic perspective, I was able to reevaluate my own personal suffering and concentrate on the experience as part of something more complicated and holistic. In this way I am also forced to reevaluate my impact on other systems, and morality has come to mean something far more personal and subjective. While it would be impractical as a self-preserving being to wholly free myself from prejudices about others that might help me avoid future suffering, I have come to subject myself to such rigorous self-critique concerning my motivations in all things, that there is seldom a time I am unable to find empathy for the actions of others. What has become important however, is the balance required in harmonizing my motives, my empathy, my perception of the motives of others and the larger cultural motives at hand. 
My creative endeavors revolve around a respect for the delicate balance we walk as spirits of humanity and as animals of instinctual drives and passions. Our method of integrating these elements within a society is called communication. However, because communication necessitates both subjective and objective reasoning by no less than two human parties, the reception and transmission of information becomes a subtle art of interpretation. In every act of communication, there is simultaneously the human desire to unite and coalesce and the animal drive to individuate and self-preserve. Thus, power is a question deeply embedded within the human animal as we communicate. Even as spiritual beings our idealistic plans are threatened by a fear of disempowerment. The most grounded idealist when pushed too rapidly and intensely beneath the power and will of another, experiences the change as suffering. As a result, the human animal can spend his entire life asking how concerning power. I prefer instead to ask why.

As human animals, we are subject to the demands of survival. As human spirits, we build rules, structure, and knowledge in dedication to preserving the collective society. But often we forget we are human animals as well as human spirits. Failure to acknowledge, honor and preserve both, often opposing forces of nature results in the deep suffering of individuals and society. In our arrogance we ignore that we are subject to a social food chain just as we as physical animals are subject to a food chain. Introspection then, must be the cornerstone of human balancing, which is experienced as peace.

I say balancing because this peaceful state is indeed, not static. It is an amorphous, transforming, un-nameable thing. It moves cyclically, distorted by fractal cycles and counter-cycles. It is a complicated, holistic web. It dies and is reborn ten times before we can make a recording. It undulates. We are mesmerized. We are terrified. We 
are it. We are inside it as well as outside and the thing must, by its own nature, form the shape of a circle when viewed with a detached or objective perspective. However, we must also view the shape of the world also from a subjective perspective. To self-preserve we as individual subjects differentiate objects such as "apple" and "snake." For as animals just as individuals, we find that one shape preserves us and the other consumes us. The shape is retained as an image and we are doomed to experience each shape through the lenses of morality and aesthetics simultaneously. Whether the serpent is evil or ugly, good or beautiful, is an anthropocentric estimation. What truth remains is that the serpent and the human each possess a unique shape and need to self-sustain, just like the apple. All those shapes are repeated and scaled, born, consumed and repeated again within the shape and gravity of the universe. We too, as humans, are shapes within that universe, even as we pull against it.

In a certain sense, the human propensity for idealism is what causes suffering. For when we mass-produce the apple to feed our society and exterminate the snake we perceive as a threat to our collective human health, we acknowledge our species as superior to all others. When we perceive "self" as a collective, we begin to classify "other" as that which is either useful or harmful to our species, because at a base level, the "self" is driven to sustain. From this standpoint of "self" as a society we reach the pinnacle of our delusion that we are not animals. It is only when we acknowledge our interpretation of the world around us as one of many possible lenses, that we can be critical of that lens. And only when we can critique our interpretations can we be human. Therefore to be human is to also acknowledge and understand, not to repress or delete, the animal within. 


\section{WHAT IS THE ROLE OF THE ARTIST?}

What draws a person to study art in the Western world? For some, the impulse to express their individuality finds its medium in the creation of art. This is important on a metaphorical level; just as a baby individuates itself from a mother's body, lives and finally disseminates itself into the body of the inorganic earth, so the artist finds his voice and extracts his ego and personality from the collective, eventually to be subsumed by a genre, movement, company, or death. For others, the attraction is in the capacity for social change as art can be a very primal form of communication, affecting the proper audience at their core. Some find therapy in the creation of art when circumstances and personality has kept their ego from individuating. Others desire to simply focus their discipline in developing natural talents. Some are not so self-reflective about why they want to study art and schooling gives a deeper insight into the place art and the artist hold within the cultures and societies of history. Though a variety of circumstances dictate the individual and societal role of the artist as perceived by both individuals and society, artists have existed as long as the human race has existed, and typically their emergence comes from some combination of these motives.

For me, art is a language that communicates the depth of my love and empathy for humanity. There is a personal relationship in every piece of my work, which reflects inversely, the work involved in maintaining personal relationships. I love to do the work because it is hard work to love people. Yet it seems so easy to love people because I am 
in the practice of doing it. Art becomes an exercise for making meaning. When we associate work with beauty, process takes an equal role to product in assessing aesthetics.

In Likeness and Presence, Hans Belting propels an interesting conundrum about the role of images and art in modern society:

It is difficult to evaluate the significance of the image in European culture. If we remain within the millennium with which this book is concerned, we are everywhere obstructed by written texts, for Christianity is a religion of the word. If we step outside this millennium into the modern period, we find art in our way, a new function that fundamentally transformed the old image. We are so deeply influenced by the "era of art" that we find it hard to imagine the "era of images." (Belting, 1994, 9)

Belting continues in describing the importance of the icon painting to medieval culture. Typically life-sized and surrounded by legends as to the origins of such portraits, the icon of a saint held a special place to its medieval beholder because "it could not be unequivocally identified as a man-made object." (Belting, 1994, 11) Portraits of saints came to hold great power. Belting further explains, "if the person of the saint did not fit the traditional patterns, there was a need to formulate the ideal the person did embody," and that "new biographies corrected previous ones to such an extent that the older versions had to be destroyed to hide the discrepancies. Ceremonial images were likewise replaced by new ones because the official ideal had to be without error. The images, after all, had to be not only looked at, but, more, believed in." (Belting, 1994, 13)

Images provided a sense of immediacy to emotional and spiritual experiences where words cannot be so exact. As Keith Micklewright states in Mastering the Language of Visual Expression, "language generally operates with "universals," requiring considerable elaboration to describe, usually rather imprecisely, the "particular." 
Drawing, in contrast, is seldom universal, nearly always describing the particular." (Micklewright, 2005, 8) Neurosurgeon Richard Bergland suggests dual, even incompatible functions of the human brain where images or "pictures" are concerned:

Modern brain scientists now know that your left brain is your verbal and rational brain; it thinks serially and reduces its thoughts to numbers, letters, and words .... Your right brain is your non-verbal and intuitive brain; it thinks in patterns, or pictures, composed of 'whole things,' and does not comprehend reductions, either numbers, letters, or words." (Bergland. 1985, i)

But American society is losing access to its intuitive, instinctual reasoning as a result of favoring the reductive function of the brain. While society becomes more reliant on the objective knowledge gathering function of the human brain, the other function atrophies. We have become a society of logic and science to such a degree that for something to be "true" it must be "objectively true." Subjective truth has come to hold a lesser value, even "falseness," as our cultural propensity to think in words and symbols creates a world that is hostile to spirituality. Even evangelists can lose their spiritual focus in favor of converting the "other side" with the power of language. The formal language employed in any academic, intellectual, or political debate reflects the writing and methods of scientists. "Truth" has become an exercise in quantitative data collection with little to no room for the irreducible influence of human experience. Likewise, the subjective function of the mind has taken on a secondary, inferior role against objective reasoning in a culture where intuition is synonymous with words like "primitive," "base" or "animal." We are a "progressive" society, and arrogantly equate "progress" and "evolution" with superiority instead of simply change. 
Historically, it would be accurate to describe the part of the human brain that reasons through subjective experience as "primitive" only because those humans lived in an era and culture prime or prior to ours. What we gain as their successors is documentation of their respect for concepts such as an afterlife as evidenced by objects subsumed with bodies in the world's archaic burial sites. Even today, the expense we lavish on the dead; their best clothing, their polished hardwood coffins, reveals our suspicion that there is something that follows the life we understand as living humans. R. Joseph, director of the Brain Research Laboratory in San Jose, CA, writes that "on the basis of a gross photographic analysis of Neanderthal and Cro-Magnon endocasts" and research elaborated in his work Neuropsychiatry, neuropsychology, Clinical Neuroscience that "archaic, early modern, and Neanderthal men and women possessed a well-developed inferior temporal lobe and limbic system - brain areas directly implicated in the generation of religious experience." (Joseph, 2001, 106)

The ancients termed the "arts" as "tools, useful to describe the universe and our place in it." (Monaco, 2009, 24) Under this heading both Astronomy, which modern culture classifies as "science", and History, touted as purely "factual," held equal placement next to Music, Dance, Poetry, Comedy and Tragedy as "arts." Reaching through the history of language we might ask how Art became so divorced from Science. "Science" has come to hold a place that is culturally separate and superior to "Art" in modernity as a result of Socratic thinking. This is the position of Germany's celebrated skeptic, Friedrich Nietzsche, as discussed in The Birth of Tragedy. Nietzsche's critique of modernity is founded on Socrates' axiom that 'Only he who knows is virtuous,' and that, 'Everything must be conscious in order to be good.' (Nietzsche, Birth of Tragedy, §12) 
while criticizing famous men whom he perceived to perform their profession "Only by instinct." (Nietzsche, Birth of Tragedy, §13) But here the power of language opens us to multiple interpretations. Was Socrates use of the word "only" illustrative of the insignificance of instinct as a human function or was he highlighting the problem of relying solely on the instinctual function at the expense of the logical function? Nietzsche continues,

'Only by instinct': the phrase goes to the heart and centre of the Socratic tendency. With these words, Socrates condemns existing art and existing ethics in equal measure; wherever it directs its probing gaze, it sees a lack of insight and the power of delusion, and it concludes from this lack that what exists is inwardly wrong and objectionable. (Nietzsche, Birth of Tragedy, §13)

Nietzsche describes Socrates as a mystagogue of science, willing ultimately to die in its defense. In this act of martyrdom, science, like religion gave birth to a human savior. Where the death of Jesus, the voice for a faith or instinct-based ethics, left a deep and iconic impression on the development of Western culture, the death of Socrates in the name of science left a literal impression. Christianity sticks with our culture because of the immediacy of images. As Belting illustrates:

God's distance prohibits his presence in a painted representation, sensually comprehended. The modern subject, estranged from the world, sees the world as severed into the purely factual and the hidden signification of metaphor. But the old image rejected reduction into metaphor; rather, it laid claim to being immediate evidence of God's presence revealed to the eyes and the senses. (Belting, 1994, 15)

However language works on our psyches in a less visceral way; it adds a degree of separation between the immediate image-experience and the abstract word meaning. Language, like image has a historic significance, but with language the genealogy is not as readily displayed. Words involve study and team practice from a subject, where an image requires only his eyes. Nietzsche further characterizes Socrates' extremism as "a 
monstrous lack of capacity for mysticism, so that Socrates could be described as the specific non-mystic, in whom logical nature is just as over-developed, thanks to some superfoetation, as instinctive wisdom is in the mystic." (Nietzsche, The Birth of Tragedy,

Nietzsche theorizes that three stimulants force us to go on living in spite of the great suffering we endure. He states:

One person is held fast by the Socratic pleasure in understanding and by the delusion that he can thereby heal the eternal wound of existence; another is ensnared by art's seductive veil of beauty fluttering before his eyes; a third by the metaphysical solace that eternal life flows on indestructibly beneath the turmoil of appearances - to say nothing of the commoner and almost more powerful illusions which the Will constantly holds in readiness. Indeed, these three levels of illusion are only for those equipped with nobler natures, who generally feel the burden and heaviness of being with more profound aversion and who have to be tricked by exquisite stimulants into ignoring their aversion. Everything we call culture consists of such stimulants; depending on the proportions of the mixture, we have a culture which is predominantly Socratic or artistic or tragic; or if historical illustrations are permitted, a culture is either Alexandrian or Hellenic or Buddhistic. (Nietzsche, Birth of Tragedy, §18)

Culture reveals a meaning for living, which is often localized. For Americans, like any other self-centric sub-entity, we are instilled with a culture that raises our own value against perceived threats to our autonomy. We learn to live in the future, to be "selfreliant", to "pull ourselves up by our own bootstraps"... we become totally deluded that we are not part of that great undulation. To be an artist in American society is to frown on the autonomy that is supposed to be earned through the trickles of money filtered through the powerful leaders of a rich corporation. To be a successful artist is to be considered autonomous among an artistic community. Belting describes the "era of art" thusly:

The aesthetic sphere provided, so to speak, a kind of reconciliation between the lost way of experiencing images and the one that remained. The interplay of perception and interpretation that is pursued in the visual arts, as in literature, 
demands the expert or connoisseur, someone who knows the rules of the game. (Belting, 1994, 16)

But as we Westerners question the cannons set by historians and the highest bids at Sotheby's, do we wonder if to exist in both cultures means to make the role of the artist serve the goals of the national culture? Knowing the rules of the game is important to the art, but for the American, pushed on by Socratic idealism and overly objective thinking, when does art become a competitive sport? When does what is fashionable, what is within the evolving rules of the game, become what is perceived as "right?" Aesthetics and ethics become indecipherable. As we become more objective thinkers, pushed on by our scientific society, we become more object-obsessed, searching for truth in the external, and product takes precedence over process. Could the consumerist mindset of Westerners be a result of "truth" becoming defined purely by objective reasoning?

Nietzsche's three cultures may also describe the role of the artist. Where Alexandrian (Western) culture at its most passionate can be idealist, logical and dogmatic, the most favorable Western artist creates art for social change. Western art at its most successful in Western cultural terms (or where it's most lucrative and sustainable) is in advocacy. Social art teaches and persuades. For a Hellenistic culture, we might find a greater quotient of "art for art's sake." A culturally Buddhistic artist might be most likely to find or create a therapeutic effect with art as life churns ceaselessly along. Though I live in America and participate to some degree in its culture, I consider my artistic purpose more in line with Nietzsche's Buddhistic culture. The most internally balanced artist could work equally within the artistic purposes of all three cultures, but I think of myself as a balancing force within my culture, and take a naturalist approach to exploring suffering. The role of art then is not just to make suffering aesthetic so that we 
might accept past pain more gracefully, but to provide a metaphor by which we can come to view our own lives as a work of art. Where here we see an accident next to a painful pattern, encompassing a bad decision, we see artistic intention in the whole - a gestalt. And while it can be neither objectively or subjectively determined that life is inherently meaningful, we make meaning when we step back from the canvas of life, with all its vicissitudes, and see how it was lived according to one taste. 


\section{WHAT IS AN ADYTUM?}

An adytum in ancient Greek culture was simply the innermost room of a Greek temple. Physically, the adytum was walled off and impossible to enter by chance. It was well guarded. Only the initiated could tread this holy ground, and for all these reasons a great and serious sense of awe is commanded by the space. Introspection, care and respect were preconditions of entrance to the adytum. Today's church sanctuaries are built to command the same respect. Only with this sincerity can we approach our innate spirituality. Only by holding our inner worlds, our subjective experience as sacred can we know it.

Nietzsche details the function of the adytum, and the implications of shame with regards to inner worlds:

Shame - shame exists everywhere that there is a "mystery": but this is a religious concept, which was widely influential in ancient times of human culture. Everywhere there were circumscribed areas to which divine right prohibited access except under specific conditions: at first wholly spatial, insofar as certain places were not to be trod by the foot of the uninitiated, who shuddered and felt fear when near them. This feeling was frequently carried over to other circumstances, for example, to sexual relations, which as a privilege and adytum of a more mature age, were supposed to be kept from the sight of young people 
for their own benefit: relations for the protection and consecration of which many gods were thought to be active, who were posted as guardians in conjugal chambers. (In Turkish, this chamber is therefore called a harem, "holy place," and is therefore designated by the same word usually used for the forecourt of mosques.) Thus, the kingship, as a center from which power and splendor shine forth, is for its subjects a mystery full of secrecy and shame: numerous aftereffects of this can even now be sensed among peoples that would not otherwise be characterized as feeling shame at all. Likewise, the whole world of inward states, the so-called soul, is still a mystery for all non-philosophers, after endless ages in which it was believed to be of divine origin, worthy of intercourse with the divine: it is there an adytum and awakens shame. (Nietzsche, The Gay Science, $\S 100)$

If we accept the premise that Western society has become more heavily reliant on objective reasoning, and that truth is found in the objects that are external to us as the subjects, then we may come to believe that all that which is internal is unknowable. For when we reach into souls, there is nothing tangible to study, and from a scientific standpoint, that information is off limits, even unnecessary. Where product is the measure of an objective study, process is the measure of the subjective. Memory and myth provide us knowledge of this process data, for as individuals we recall sense, feeling and experience as memories, while myth gives an historical indication that past people at every stage of human culture have encountered those same experiences. While objective reasoning explains things, subjective reasoning explains our relationships to things. 
The Biblical book of Genesis provides Western culture with two foundational adyta in its powerful mythology. The first humans, like infants hearing their stomachs growl for the first time, are given nourishment from the trees of the field by the parental force of God. The mythology of this story provides a metaphorical companion to human development, and for this reason is a powerful tool for helping us understand the chaos of our world. God nourishes and feeds the infants, reflecting the first bond of parent and child, as the heavenly parent begins preserving the lives of the earthly newborns. But in this act, a relationship is formed; the reception of sustenance to one party requires the transmission of sustenance by the first. The concept of power is thus introduced. To live, the baby discovers it must rely on others. To keep that power balanced within the relationship of the two parties, the Tree of Life and the Tree of Knowledge, which are as equally nourishing as any other tree in the garden, are made forbidden. Knowledge changes us. And to change one shape is to change its relationship to another. Knowledge then, like sustenance, must be fed at a controlled pace. The limitation of children's knowledge is preserved as the human ideal of innocence, but from the unconscious, instinctual standpoint of adults with disintegrating health, the natural vitality of children must be balanced by the animal ideal of ignorance. Knowledge is power. 
THE POWER OF LANGUAGE

If knowledge is power, then language is the expression of power, often to the degree that language even creates knowledge. As words are created, connotations become subtler, and meaning gets obscured. By the same token that language is an imprecise tool for communication; it becomes a sneaky tool for the transmitter of the language to disempower the receivers who find themselves slowed down in the decoding process. Lawyers thrive on the imprecision of language.

The following passage by Keith Micklewright illustrates the dual development of language:

Written language has developed in two forms: phonograms, where signs represent the sounds of spoken language, and pictograms, which represent ideas and are unrelated to the sound of the language. Pictograms are self-explanatory (1.3), but phonograms, more commonly described as an alphabet, can only be understood by knowing the spoken language. (Micklewright, 2005, 8)

Poetry and etiquette add another confusing element to language as a tool meant for communication. We are unconsciously aware of the power of language. Anxiety about causing imbalance in a dialogue prevents us from speaking as efficiently as we might if human feelings were not at the other end of our imprecise communication tools, so we invent poetry, euphemism and etiquette to cover our indiscretions. In this process we further obscure language's scientific usefulness and language becomes art.

It is also at this intersection however, that we observe the birth of art and music. 
Music expresses experience in a way which no literal meaning can, because it does not reflect meaning, but the treatment of the meaning. If the purpose of language is communication and communication is the relating of two human spirits, then when we realize the impotence of words to convey all possible meaning, we look to the presentation of language. Meaning is also conveyed through fonts and phonetics. Why does the word "love" seem so phonetically mellifluous to the Western ear? With the shape of the tongue flirting through the open mouth transitioning gently to the complex vowel that gradually ends in a lingering brush of the teeth against the bottom lip as the un-aspirated "v" completes the prolonged single syllable, there is natural music to language. But the music is not inherent. "Love" conveys a human ideal, so we treat the word aesthetically. The same person will pronounce the word differently when they are heartbroken and bitter than when they are indeed in love. The treatment of spoken language I am describing is usually referred to as "tone," but I believe that though tone does reflect the attitude of the speaker, it also reflects his/her aesthetic values. This becomes apparent in language when someone describes the behavior of another as "ugly." Our brains are wired to communicate aesthetically while we communicate logically, because we are simultaneously beings of logical objectivity and spiritual subjectivity. 


\section{ON LOVE, SELF, AND OTHERS}

Oscar Wilde said "To love oneself is the beginning of a life-long romance," while Kierkegaard reminds us "Don't forget to love yourself." These adages respond to a maxim found in nearly every ethical tradition in history. The "ethic of reciprocity", or more commonly, The Golden Rule, finds expression in many religions. However, Christianity as the leading power in organized religion claims the genesis of The Golden Rule by attributing it to an utterance by Jesus of Nazareth, imploring, "Therefore all things whatsoever ye would that men should do to you, do ye even so to them." (Matthew

\section{7:12, Revised Standard Version)}

The Bible provides a peculiar conundrum with loving your self. In the celebrated book of Matthew, the author narrates:

Hearing that Jesus had silenced the Sadducees, the Pharisees got together. One of them, an expert in the law, tested him with this question: "Teacher, which is the greatest commandment in the Law?" Jesus replied: "'Love the Lord your God with all your heart and with all your soul and with all your mind.' This is the first and greatest commandment. And the second is like it: 'Love your neighbor as yourself.' All the Law and the Prophets hang on these two commandments" (Matthew 22:34$40, \mathrm{RSV})$

Scholars and believers alike can no more than assume that the modern reader of this passage "loves" himself or herself, but this very basic assumption is almost never addressed anywhere else in that revered tome. In Ephesians, a slight clarification reveals "no one ever hated his own body, but he feeds and cares for it, just as Christ does the church." (Ephesians 5:29, RSV). So hate then, implied as the opposite of love, means to 
not feed and care for your physical body. Should your "neighbor," (another ambiguous term) or perhaps any individual you take notice of, be dying from starvation, feed him what you can also feed yourself. It seems fairly rudimentary - don't allow each other to die of starvation. No human animal with any grain of human spirit would deny this seemingly simple show of empathy. But where is the line of distinction drawn for "neighbor?" Do we stop at the loved one sleeping in the room next door, at the house down the street, at neighboring countries or planets? At animals with whom we cannot verbally communicate? How far are we asked to extend our empathy? How should we love others as ourselves if we know neither the boundaries of "love," nor "self" nor "others?"

C. G. Jung, a man of great humanity, spirituality and science, in addition to the eminent legacy he left in the field of psychology, suggests:

The recognition and taking to heart of the subjective limitation of knowledge in general, and of psychological knowledge in particular, is a basic condition for the scientific and accurate estimation of a psyche differing from that of the observing subject. This condition is fulfilled only when the observer is adequately informed concerning the compass and nature of his own personality. He can, however, be sufficiently informed only when he has in great measure freed himself from the compromising influence of collective opinion and feeling, and has thereby reached a clear conception of his own individuality." (Jung, 1964, 17)

Plato said "Know Thyself." And through this history of moral edicts, we are left with three ambiguous concepts; "love," "others," and "self," and as individuals, consciously rank them according to our cultural and personal ideals. We rank them unconsciously too, so what Jung suggests by the "compass and nature" of personality is a method by which we undertake to know ourselves, by which we render ourselves capable of loving others as ourselves. I take issue with the presumption that to "love thy neighbor as yourself" somehow lends itself to mutual relationships. According to nearly every ethical tradition 
love also takes sacrifice of the self - a conflicting moral. As individuals we fail to properly respect idealism. What we idealize and what we can discover through others may be not be one in the same. Our ideals can be transformed when we love another in spite of their distance to our ideals. Or as a method of fitting those we love into our system of ideals, we project ideals onto them, so that we might love them in spite of the difference. We create for ourselves beautiful delusions of others. We translate others so that we may identify them as our own or part of our selves. We create reverse delusions for "others" so that we villainize that which we perceive as threatening to our own identity. As Rouchfoucauld puts it in Reflections; or Sentences and Moral Maxims $(1665-1678)$ "Self-love is the greatest of all flatterers." And flatterers deal in delusion.

When we are balanced individuals, we love ourselves both idealistically and with a peculiar routine of discovery. Yet we begin casting parts for our selves and others. We define societal rules to avoid discomfort, and as a society we call ourselves just or right or more human. However, to be human is to be just one of many animals. We create structures to live in with each other and ignore the structures of our own beings. By drawing these lines between the "evolved" human mind and the instinctual drives that are inextricably connected, we become unconscious that we, like all animals are locked in a "food chain". The powerless tend to stay powerless and the world's money fills the pockets of the same precious few animals at the top of the food chain. We are as yet still animals. But as we look into the eyes of our pets, do we not suppose that animals, those "base" and "primitive" individuals, without a word of human language love us? Couldn't all animals, just as our selves be creatures that "love?" However, none of us can interpret from another, neither with science nor with language, what is meant by that word. And 
so, with scientific curiosity in equal measure, we must always respect and rely on our natures, our instincts, our personalities. Herein lies our system of checks and balances. Do unto others as you would have them do unto you, but because you have words as a human, explain unto others, the specifics of your ideals. You might learn so much more about yourself, you find less need for the term "others."

In the microcosm of intimate relationships, I still make an idealistic attempt to erase the power plays. Spirituality, which has been inextricably linked to organized religion, has become subject to commoditization as the Christian church, in order to survive the industrial revolution became a business founded on money and power, and morality is bound up in the history of the church. In The Gay Science, Nietzsche begins breaking down the concept of morality, which will eventually become the focus of his Genealogy of Morals. By calling into question the foundations and histories of every societal more that has every been considered by and large "good" or "virtuous," and by contrast that which is "bad" or "evil," he uncovers the hidden fallacy of an "absolute" or "universal" truth. Every authorial account of knowledge in history rests on some faulty premise. "The Madman," depicts a misanthropic advocate of humanity ringing the church bell above a city who is deaf to his passion. A self-portrait of the author and the mouthpiece of his infamous pronunciation that "God is dead," the madman continues, "and we have killed him." (Nietzsche, The Gay Science, §125) Nietzsche's claim is that by creating the world we presently live in, the world of consumers, of industry, of technology and science as "empirical truth" we have created an environment that is so hostile to the immediacy of the ancient beliefs in God, that we can no longer accept the idea of God as the ultimate authority. Those judged as "immoral" are no longer at the mercy of a God who will smite 
him with lightning, because science explains the phenomenon of lighting and as a natural condition of earthly weather, it does not have the discretion to smite. Even those claiming religion and service to God, Nietzsche insists instead to be non-believers worshipping a shadow-in-memoriam of the god who has perished at our hand. He laments the death of God and the mythology that dies with Him, for as we lose our faith in mythology as a valid tool for making sense of the world, we kill spirituality. The loss of the beautiful delusion that was for so long, the glue of pre-modern society must result in the ungluing, separation, classification and categorization of mankind. 


\section{ON SCIENCE AND CLASSIFICATION}

The goals of science are to observe, test, analyze and record the phenomena of nature so that classifications and predictions can be made to further benefit mankind's understanding of, and interaction with the natural world. Simply put, the goals of science are the same as the goals of religion - to make sense of the world. This is a noble enough endeavor, but with the practice of classification, science as a process must necessarily categorize humans. In the process of classification, our scientific conscientiousness masks the result, which is the manifestation of the food chain as social class.

Instinct necessitates that the individual classify those external to him/her by rank. This is as natural and as unconscious to people as it is to birds of prey as they decide which animal is small enough to lose the fight for its own life but large enough to provide the predator the sustenance to continue his own. As humans we structure our societies so that small people do not need to die to sustain those larger than them. However, in our supreme arrogance we classify the human animal as above or outside the laws of animal nature. With this layer of ambiguity, humans begin to blame each other for their dystopia. We create structures to facilitate freedom, but the animal drive for survival expresses itself through humans "Will to Power". Survival and hoarding mentality become inseparable in the mind. Survival is an instinctual drive, largely unconscious and lacking in self-reflection. In fact, instinct is thoroughly incapable of acknowledging "self" at all, nor anything inward. Instinct relies solely on relationships to external entities. In its 
purest form, instinct, like pure logic is dangerous to people. We encounter chaos, we suffer, we remain unlearned. We do not individuate. But because we are human, we can theorize and abstract, create structure, empower morality and enact culture. We create structures to facilitate equality. We become idealistic, optimistic, communal, dare I say universal. But universality too, is merely a projection, a feeling and an experience that is unique to the development and perception of an individual. Ironically, "universality" therefore means nothing in the objective sense, despite the fact it seems to mean everything. Of modern man consumed by his unconscious Socratic culture Nietzsche presents a warning, "At present, however, science, spurred on by its powerful delusion, is hurrying unstoppably to its limits, where the optimism hidden in the essence of logic will founder and break up." (The Birth of Tragedy, §15)

In taking science as a lens, the methodology seems specifically un-human. We think of the approach as cold and detached. The goal of the scientific method is not to see what we want but simply to record what we see. So what happens when we look into the microscope and see nothing? We reach for another lens. We raise the magnification. We lower the magnification. We change our lens until we can interpret. But it is not because there is an objective something to be interpreted that we finally see through the correctly chosen lens. It is because we want to understand that we feel understanding. The goal is still happiness. People are "objective" and "scientific" for the same reason that they are "religious" or "sympathetic." There is great joy in the feeling of understanding, in epiphany.

To say "epiphany" is nothing more than an emotional climax, a release of chemicals in the brain at the end of an arduous attempt to "understand" might sound 
hideous to one under the objectivity delusion, but it's also a testament to the aweinspiring microcosm of our human brains. Epiphany is the emotion that occurs when we make conscious what was just previously unconscious. Just as emotion and instinct are reducible by science, so is science reducible by emotion and instinct. 


\section{THE DEATH OF MYTHOLOGY AND THE REBIRTH OF ART}

If mythology in its naked form can only be seen now as mere entertainment, where does the modern thinker find religion? He stimulates that part of the brain by culturally acceptable means; through sex, drugs, and recreational activities geared to drive up dopamine in the brain. How does he find morality, if religion no longer has the authority to enforce retribution? Beyond culture, tradition and what consequences the law presents for his actions, personal rewards dictate his/her behavior. For the modern Westerner, the only adytum is the de-mythification of science.

Nietzsche accepts this great loss for humanity, and without nihilism, but instead with a cheerful optimism, provides a solution through art. We must become the artists of our own lives, creating from the raw materials of suffering, joy, pleasure, and pain our own personal guidebook for living. We must be able to look at our lives in terms of aesthetics in addition to the terms of rules we live by. In fashioning this life as artwork, we the artists must be able to step back, palette in hand, and look at the whole of our lives and see the gestalt of choices made intentionally by a "single taste." In this way we become improvisers and transformers of self.

As Friedrich Nietzsche suggests, I too believe we as individuals must be able to live our present lives as if we could live that same life verbatim, with all the same ups and downs, again and again for eternity, like a favorite novel. Prior to my introduction to the beautiful words of the philosopher, I had a lay description of this life philosophy. I 
must live in such a way that I never have any regrets. My decisions will be slow to allow for process and experimentation but intentional in execution. In spite of what many would charge me with as "poor choices," I have always been able to reflect on my life's decisions and direction with the honest belief that if I were given the choice over, I would not have already acquired the experiential knowledge of having lived and suffered through the cause and effect of my actions in a given circumstance. In this way, I look at the suffering I have encountered the same way I look at collage elements for an artistic composition. It is the relationship of the elements within the composition that create the art, and the treatment of those elements as an artist that create meaning. "Only one thing is needful," Nietzsche states; "to give style to one's character." (Nietzsche, The Gay Science, §290) With the process of making and the interpretation of an object's meaning, in both cases we are making meaning. Through the practice of art, we practice meaningful living. 


\section{THE ADYTUM: AN ARTIST'S STATEMENT}

People are curious creatures. Bound by abstract thought to create societies and achieve oneness, the human spirit is logical and idealist. But equally bound is the human animal to survival instincts that operate by distinguishing self from the other. This terrible conflict of desires, both to unite and to individuate, causes suffering. The greater our suffering, the greater we perceive binaries, opposition and power.

Our dual reasoning processes, as Carl Jung illustrates, mirrors Goethe's characterization of life-rhythm as the alternating diastolic and systolic activity of the human heart. The objective process reaches outward to collect information, and therefore the external is always held at a higher value than the internal. Meanwhile, the subjective process analyzes its relationship to external objects in order to internalize them. The natural preference for one process over the other creates an extroverted or introverted personality. Jung writes:

Quite generally, one could describe the introverted standpoint as one that under all circumstances sets the self and the subjective psychological process above the object and the objective process, or at any rate holds its ground against the object. This attitude, therefore, gives the subject a higher value than the object. As a result, the object always possesses a lower value; (Jung, 1964, 12)

Here, one may be inclined towards offense that perhaps Jung is accusing the introverted type of self-absorption, even disinterest in others, but we must understand that what Jung is attempting to do is characterize the subject/object relationship, a key component, both of creating and appreciating art. For the introverted type, information is experienced and 
calculated as an affect on the subject. When one is an artist, he/she exhibits the same interpretive process. Jung continues for the case of the introvert and the extrovert, respectively:

...the idea is the essential factor; or it is the object of a feeling, where, however, the feeling experience is the chief thing, and not the object in its own individuality. The extraverted standpoint, on the contrary, sets the subject below the object, whereby the object receives the predominant value. The subject always has secondary importance; the subjective process appears at times merely as a disturbing or superfluous accessory to objective events. It is plain that the psychology resulting from these antagonistic standpoints must be distinguished as two totally different orientations. (Jung, 1964, 12)

As these dual functions serve the individual, individuals serve the same dual functions in the personality of a society. In turn, societies serve the dual functions of the heart of the world's people, of all the world's living things, and in turn, the heart of the universe.

Suffering may always appear as shadow against light, for what we are able to see, like Plato's allegory of the cave, is always conditioned by what we cannot see; what is unconscious. In this light, morality can never be purely logical, purely instinctual, good and evil or black and white. The adytum of our unconscious represents the knowledge we are constantly uncovering, what we are not yet allowed to know. But for every thought we make conscious, we again bury another in unconsciousness. Suffering for the individual must become an artistic element - the raw materials of making meaning. Only in the gestalt of oppositions do we find the functioning of our hearts.

For these reasons I have created an intimate space with my exhibition, The Adytum. A dark curtain circumscribes the space while church pews allow limited seating for no more than six individuals. Optimally, one person at a time will sit solemnly within the adytum as the film encourages contemplation of body as instinct, love as idealism, and spirituality as a communion of necessary oppositions. The affected viewer claims the 
adytum as his own place of respect, perhaps even of epiphany. But even as he/she sits alone, the viewer is surrounded by the phantom presence of others as five empty seats create a familial void. My hope is that the viewer leaves with the desire to initiate others into his/her adytum, for this is how we love.

I have created The Adytum in love and respect for people. The Adytum is not for everyone all at once, but it is for everyone. The film lasts for one brief hour, with the final $10-15$ minutes dark and image-less. This is the systolic completion of the spiritual heart metaphor as the viewer gently transitions back into the objective world to make room for the next cycle.

Because transformation is the key component of meaning in my work, I find my most powerful expression in the time-based medium of film. Film requires an active engagement of its viewers, but is also constantly rewarding them with new images. The speed at which the images are revealed becomes important to the meaning as a literal and logical narrative interacts with the treatment of that development. Both aspects of film happen simultaneously and dependently of the other in the same way that our subjective and objective processes work. The emergence of film may reflect the deep interest of people in their dreams, as it is the art form most closely capable of rendering the image/feeling experience of dream narrative. Dreams reflect the important of mythology in making meaning. Dreams are the Rosetta stone with which we translate the unconscious to consciousness. Mythology allows us to share our unconscious as a collective, and is thus necessary for human spirituality.

I have described the ways in which "truth" is not wholly objective, static, logical, or universal, but rather a balancing of objective observation and subjective experience. 
Morality, then cannot be drawn in black and white, and extends beyond good and evil. In this light, it is sufficient to conclude that life is not inherently meaningful, but rather, in our transformations we learn as in art, to see gestalt, the artist's intention, or a life lived by one taste, and thus translate meaning from our lives.

Nietzsche's view that Socrates has influenced our culture so profoundly that scientific, objective reasoning has arrogantly stepped up a superior truth, as the truth, reflects my suspicion that Western society, the society in which I am a part, has taken on the personality of the extravert at the cost of its collective subjective wisdom. It is not my intention to replace the role of science with religion, but to point out the objective reasoning which is the tool and trend of both. In either sense, Science and Religion are not opposing forces, but organizations of humankind to understand the world. However, in this shift towards objectivity as ultimate truth, our whole society moves further from center. We have even in religion, become less spiritual, less human.

As a scholar and an intellectual, influence by the cultural personality that favors objectivity, I find myself resistant to mythology. If we are to find truth only in empirical observations, mathematics and science, we are bound to see technology as our god. Mythology can no longer hold a place in the realm of truth, and has been relegated to mere entertainment. Movie theaters hold the place that was once held by churches, and the two spaces differ very little in presentation. We used to sit in the dark facing an illuminated picture of something that made us quiet and contemplative, and that we called church. We absorbed stories and mythologies about characters which we understood better with our instinctual hearts than our logical minds, and that we called The Bible, The Q'uran, or even The Illiad. What these characters mean to us are as real as the text 
with which they were written. The problem is that, culturally, we are trained to treat them literally, and here, as beings of spirituality, is where we miss the boat. The popularity of movies and theaters remind us of our need for mythology to be spiritual. Their role as entertainment reflects our culture's lack of values for subjective truth. Here, the artist finds her place as negotiator and balancer. I too, have the truth. 


\section{THE MYTHOLOGY OF THE ADYTUM}

Like a candlelit shrine, the major component of The Adytum is an illuminated portrait of making meaning from suffering. In the film, there is a diluted narrative. In the diluted narrative there is a history of morality. In the history of morality there is a group of women who serve the dual role of nun and as prostitute. Bullough and Brundage write "Inevitably most Christian writers agreed that, while prostitutes were to be excluded from the Church as long as they continued their profession, prostitution itself had to be tolerated as a necessary evil. In fact, Saint Augustine argued that if prostitutes were not available, established patterns of sexual relationships would be endangered." (Bullough and Brundage, 1982, 36) Modern culture would see this pairing as hypocrisy, but in the pre-literate religion-governed culture of Medieval Europe, women's marginalized circumstances necessitated that they fill the role of mother, nun, or prostitute. Often one role was simply not enough and it was common for even the most respectable women to engage in prostitution. With my particular set of human experiences, I could empathize with the sort of women who might fulfill roles as both spiritual leaders and sexual healers. A certain type of service personality, whether masochistic, self-destructive or dutiful, is often present in both the role of nun and prostitute. Today, we assume women who enter professions in sexualized entertainment such as pornography or strip acts do so by choice, but even today that's often not the case. It might take more than knocking off the headdress of a respectable lady in the streets to demote her to a lower status in 
society, but what rapists do in the streets of the inner world of their victims today is as hidden as any adytum.

I saw the women who occupy the brothel/nunnery in The Adytum as serviceminded caretakers and literal lovers of mankind. Forsaking societal respect for a life which allows them to continue a life of spiritual service in a way which allows them to remain autonomous, the convent contains itself in a modest tent in the woods. For this reason, the stylized movements of the three nuns, paired with the unchanging expressions of their head masks give a religious and ritual aspect to the act of prostitution. Though money is exchanged for the fawning affection of these ladies of the night, there is a respectful and empathetic communion that takes place in the interaction of the brothel visitor and the prostitutes.

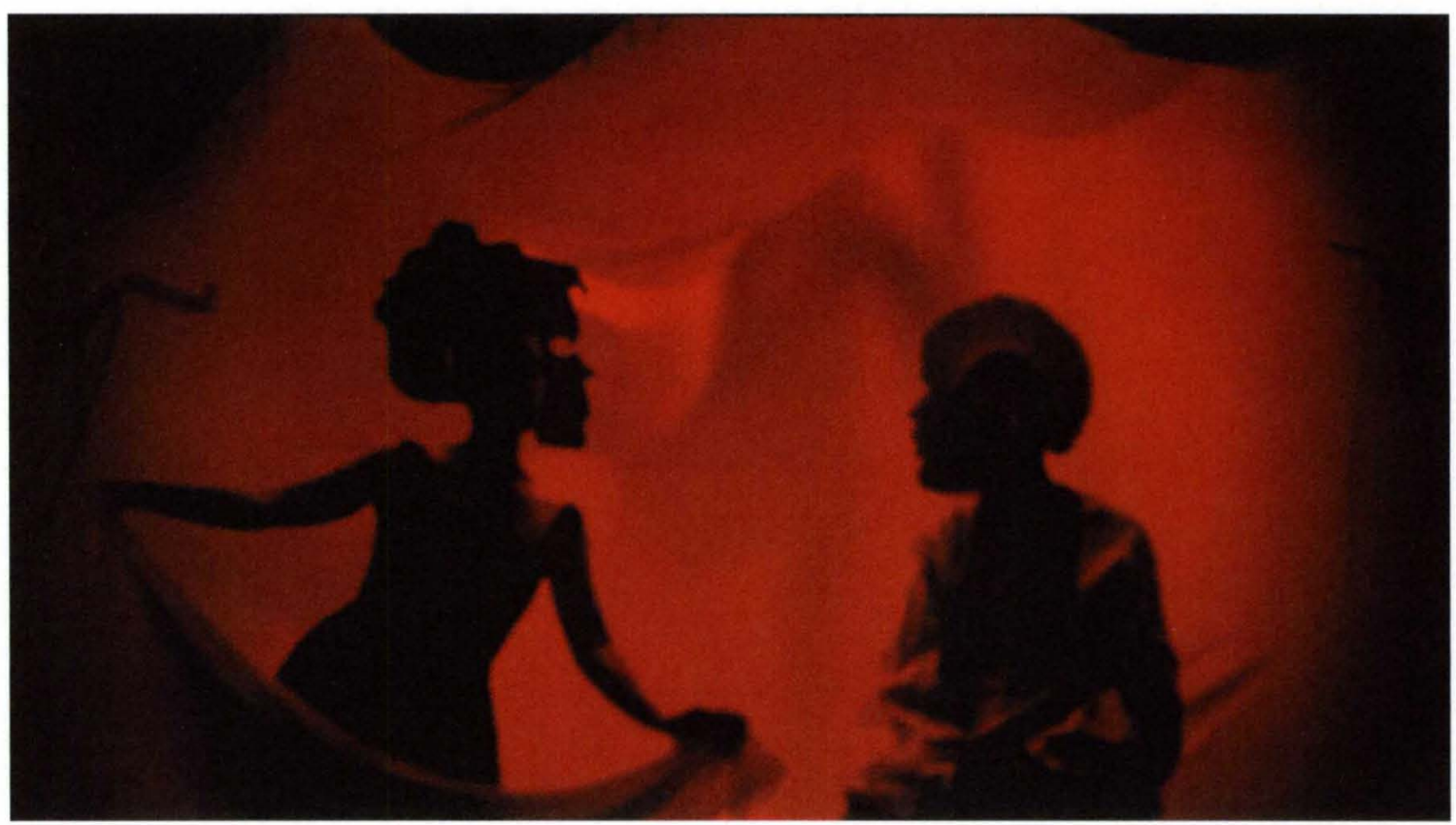

With my image and sound world, I recall a culture that contrasts our current culture. Literacy, like money, creates class distinctions so that the powerless stay powerless and the powerful grow towards their limits. However, illiterate Medieval 
Europe, pregnant with the age of Enlightenment, was a culture on the verge of a great paradigm shift. With the advent of the Internet, we too are spiraling towards a paradigm shift. Information is created, distributed, and available to enormous masses of people at an alarming rate. The adytum of knowledge is being torn apart, and we move ever closer to Nietzsche's prediction about modern man as the disciple of Socrates and science. "When, to his horror, Nietzsche writes, he sees how logic curls up around itself at these limits and finally bites its own tail, then a new form of knowledge breaks through, tragic knowledge, which, simply to be endured, needs art for protection and as medicine." (The Birth of Tragedy, §15)

The opening image of the film shows a student practicing a written language that is foreign to the viewer. Immediately, the viewer is placed in a world that resembles the structure of his/her own, but can make no logical sense of it. From the very start, I wanted the Western viewer to be forced to favor his/her intuitive reasoning to comprehend the story I was presenting. There is plenty of logic to the film, as symbols are created and words take on meaning through repetition, but I wanted the viewer to have to start from scratch and engage with the images and mythology more like a preliterate human would.

My film, The Adytum explores how people (especially women or minorities) make meaning out of a marginalized life in society. The tragedies of the marginalized create the underdog characters of mythology. Mythology forms the culture people make and need. This act gives meaning to life (rather than life being objectively or universally meaningful in the context of societal laws) and we become more fully human or transcendent. But at the same time, morality is prescribed by those in power which although probably unconsciously, makes a slave class for themselves to metaphorically 
feed and survive on as the bigger animals in the food chain. Then the slave class is blamed for their station by the powerful class and the circle of life, as ugly as it may seem to an idealist, preserves itself. Class is inevitable and glossed over by human idealism, especially Alexandrian idealism, as something people can transcend with enough effort and presence of mind. I disagree, and believe, like Nietzsche that chaos is necessary to making meaning and we discover meaning in life through art. 


\section{THE PURPOSE OF THE LANGUAGE IN THE ADYTUM}

As previously discussed language is meaningful in equal parts, symbolic logic and artistic treatment. Creating dialog between characters in a fake language serves multiple purposes. First, I put the spectator at a disadvantage in order that they might be open to empathize with the underdog characters no matter their specific moral beliefs. When we watch foreign films without the luxury of subtitles, we are often still able to interpret meaning through the treatment or delivery of dialogs between characters. In this way, we are actually hearing the relationships inherent in spoken language in the same way we hear them when we listen to music. The second reason for the fake language is to separate what we hear from what we think we hear. This concept mimics the pedagogical functions employed by Betty Edwards in her book Drawing on the Right side of the Brain. Our brains filter out visual information that isn't required for recognition of objects. Therefore when we try to draw, we create icons instead of a more realistic interpretation of the object we want to replicate on a surface.

With language we employ the same logical economy with the alphabet and words. Our brains are trained since birth by modern culture to recognize logical patterns and symbols, and think in language to infer meaning. In preliterate societies, such as much of Medieval Europe, people had to think in images. It was an era of images. Saintly portraits provided signposts for community events specific to the icon of that particular saint as well as indicating the presence of that saint in the location. This lent a sense of 
immediacy and community which literal thinking has unraveled. By creating a fake language, both with phonic and pictographic arrangement, I remove the distraction of literal meaning and require the viewer interact instinctually, emotionally and with empathy for the characters.

The script, written in both English and the fake language, Cvellish served its purposes as needed for guidance, rather than as a literal manual, for the script is just words. The speech and movement for the film's characters were recorded separately, at different times, and often by different people. In each recording the treatment of meaning, not the literal meaning, pronunciation, or technical presentation of skill, was valued as the most important element of the art. Some people had a difficult time with "pronouncing" the language because of their respect for literal meaning, but once they got in touch with the sentiment of their utterances, the words began to glide over their tongues and natural musical language was formed. The process of communicating with this language created genuine relationships, which are audible to the viewer. 


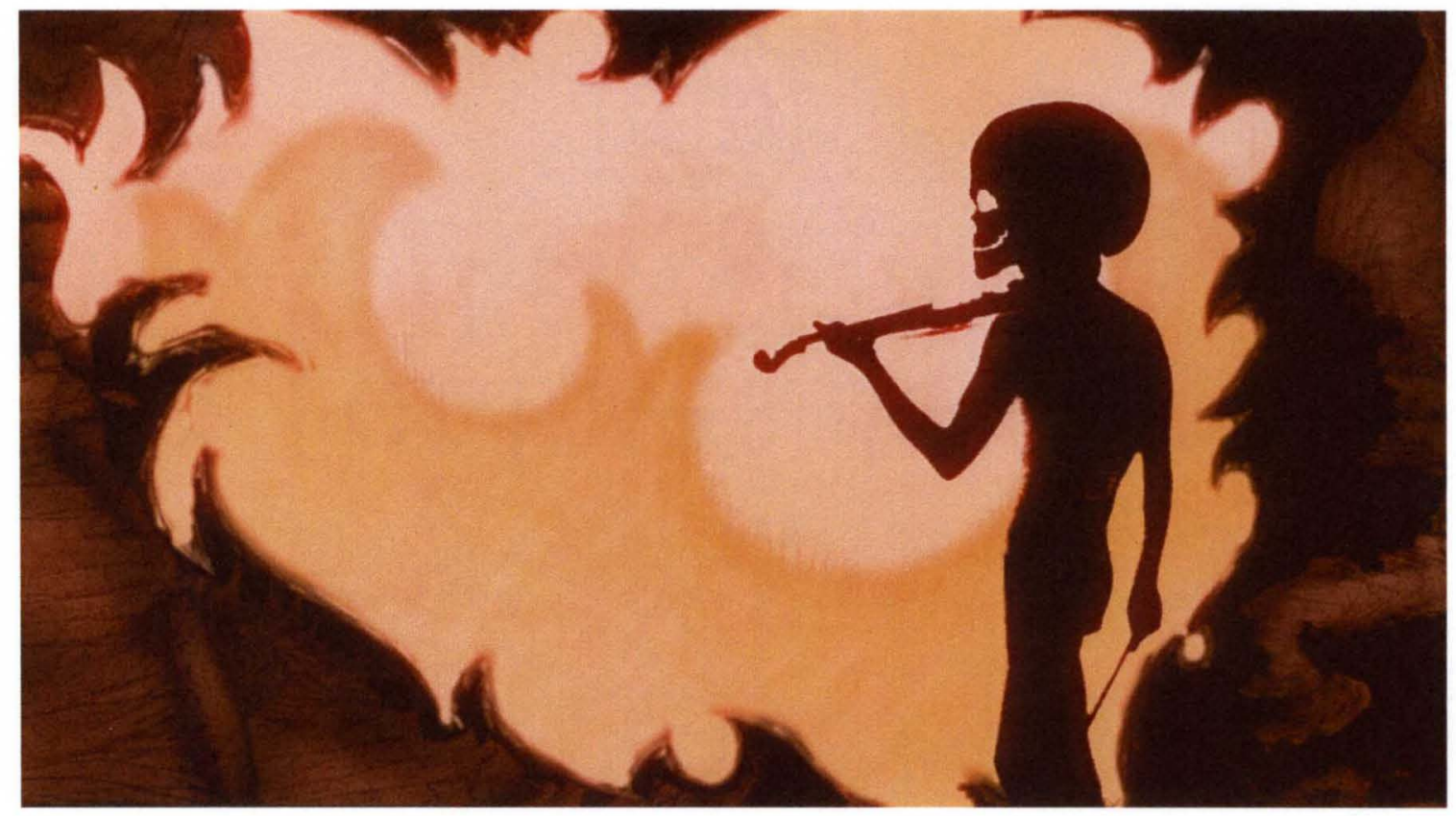

The images of The Adytum allude to traditional depictions of the virtue of the power of the mind over the body. Recalling the death and the maiden motif made famous by Hans Baldung's woodcuts, together with images of dark, church-like interiors, the prospect of a morality tale insinuates itself. As a skeleton beckons a young woman, the film's protagonist, Kloeshi, the viewer is set up to anticipate judgment and retribution. Perhaps the young woman suffers from vanity or lust; afflictions or "sins" that result with the power of the body over the mind. Through the economy and tradition of cultural images, the viewer is immediately given over to caution, even suspicion towards the skeleton who surely symbolizes death, the greatest unknown. For with the image of the skeleton we see a human spirit separated from its corporeal vehicle. 


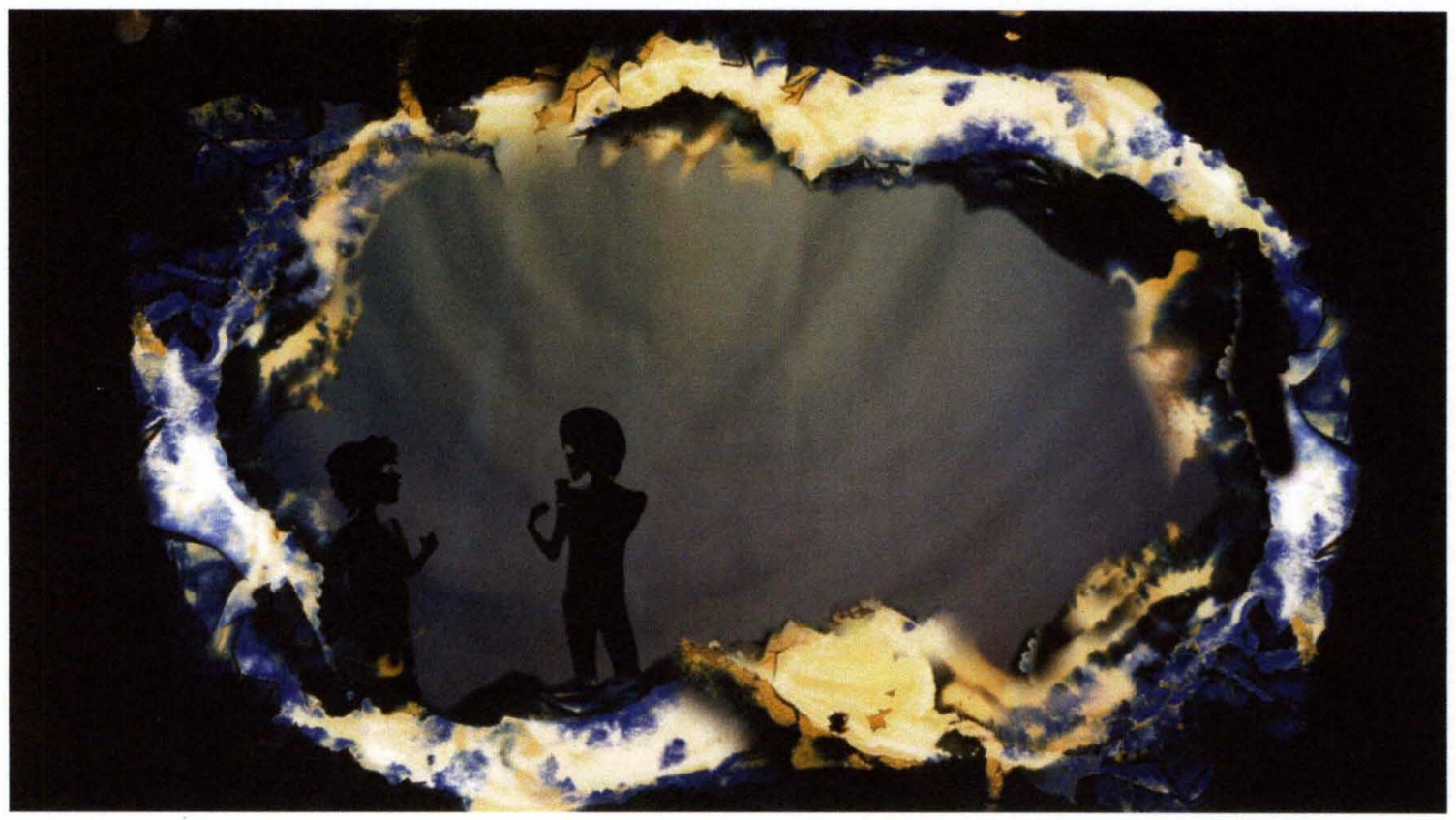

The skeleton befriends Kloeshi, even teaches her music and language, inviting her to learn love as she develops tools to empower herself against opposing forces. The glorification of the character comes not through themes of body over mind as a reaction to mind over body, but simply through curiosity, improvisation and artistic self-making. She defines herself gracefully through external and internal contemplation and makes a gestalt of her suffering. The friendship with the skeleton reveals the sincerity of her bond to her own inner structure as she makes sense of the external structures. At the same time a sense of foreboding follows the skeleton's gentle "come hither" gesture, which become more violent as the corrupt monk and the power structures of her actual circumstances confront her. 


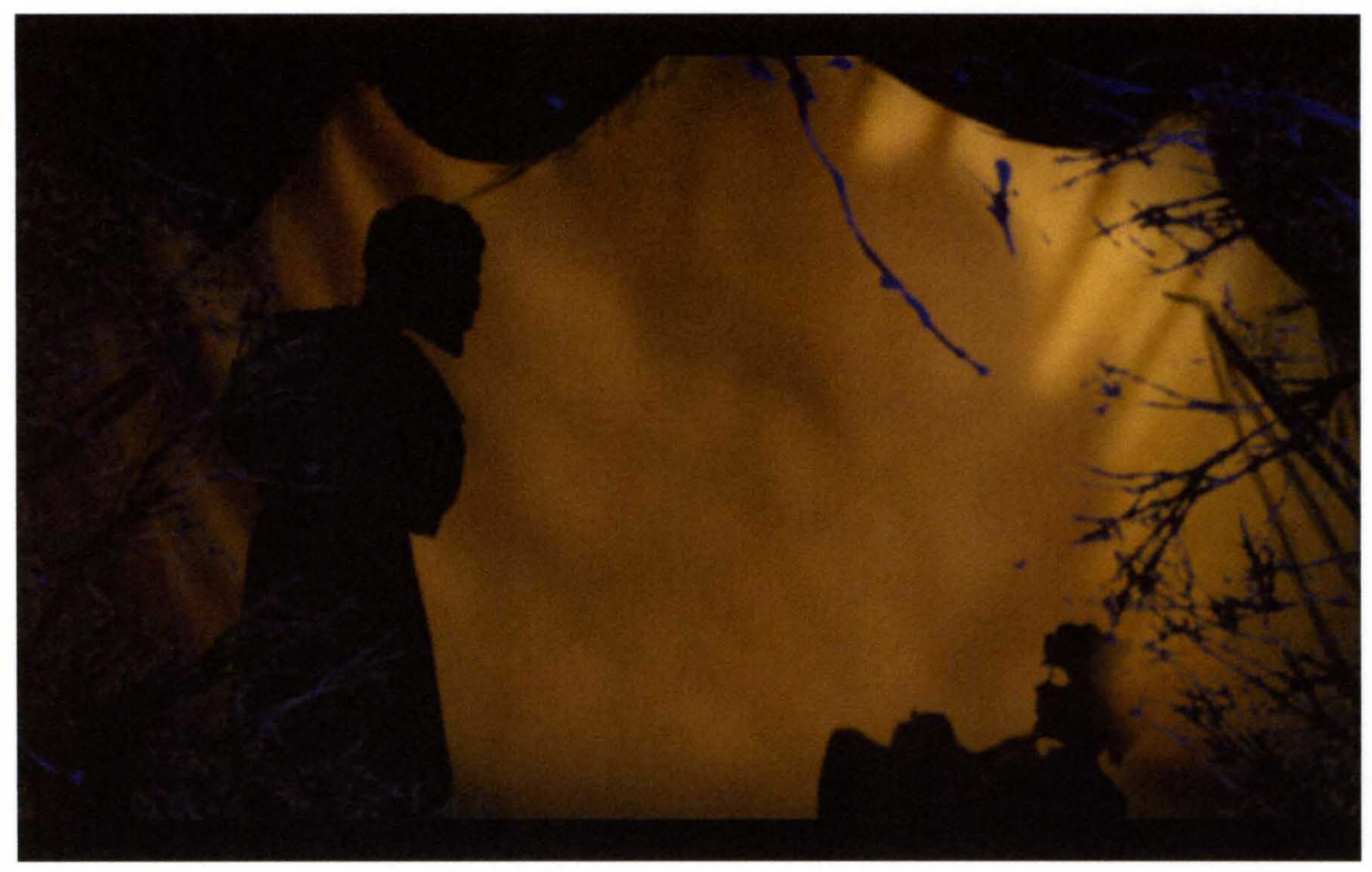

While it is appropriate to associate the image of a skeleton with death, I think it is inappropriate to associate death with immorality or retribution. The recognizable form of the skeleton, specifically in silhouette, reveals the seductive element of mystery in death. In both the case of religious ethics and Socratic ethics, the demonized element embodied by the human skeleton is simply that which remains unknown. Through the lens of Christianity, the locus of the demonized unknown is within our own body. R Joseph has described the role of the limbic system in human spiritual experience with various historic examples documenting human "out of body" experiences. Astral projection in Buddhist religious practice, measures to a great degree, the success of meditation. Much of religious experience, the closeness to God is associated by the individual's feeling that they are "outside" their body, an implication of the temporal lobe, a facet of the limbic system in the human brain. Meanwhile, through the lens of the Socratic tradition, what we learn through reason is made knowledge when we internalize it by expressing it 
consciously. That which cannot be committed to consciousness through reason is unknowable. Therefore, the locus of the demonized unknown in the Socratic tradition is outside the body. In both instances the body creates a conflict with relation to human understanding. We know either by that which is empirically observed through our bodily senses or by that which can only be experienced as emotion, and insufficiently described by language.

When the child, Kloeshi meets the skeleton, she is only as hesitant to interact with him as any other stranger. As he gains her trust he leads her downward into a setting of organic patterns and ambiguous primordial matter. A moralist standpoint might point out that he is leading her metaphorically downward to her demise, to hell even, but there is no fire where the skeleton leads Kloeshi. There are only instinctual memories of an era before humanity. The imagery traversed by Kloeshi and her guide changes seamlessly from a recognizable landscape including objects recognizable as trees and sky to what feels more like being inside the body. It is here that the character is most deeply connected to her instincts and unconscious, but simultaneously where she is most divorced from the objective world. Out of balance, she is vulnerable to others' power in the same way the smallest animals are vulnerable to predators. The silmultaneous interaction between the masked Kloeshi and the intruding monk and the silhouetted Kloeshi and the skeleton are purposefully chaotic and confusing, for ultimately, when a predator overpowers its prey there is at once an individuation of ego and a unification of two beings. In this moment, while the monk hovers in the dominant position, his physical size shrinks while the cowering shape of the child grows as she struggles against it. There 
is no clear winner or loser in this exchange of power, but there is a climactic effect. There is an epiphany that there is more than one way of viewing the world.

Towards the end of the film, the actress's feet are seen at a white dress drops to the ground and she steps out of it. I intended this image, not as the loss of innocence, which is one way it could be interpreted, but rather as the removal of idealism.

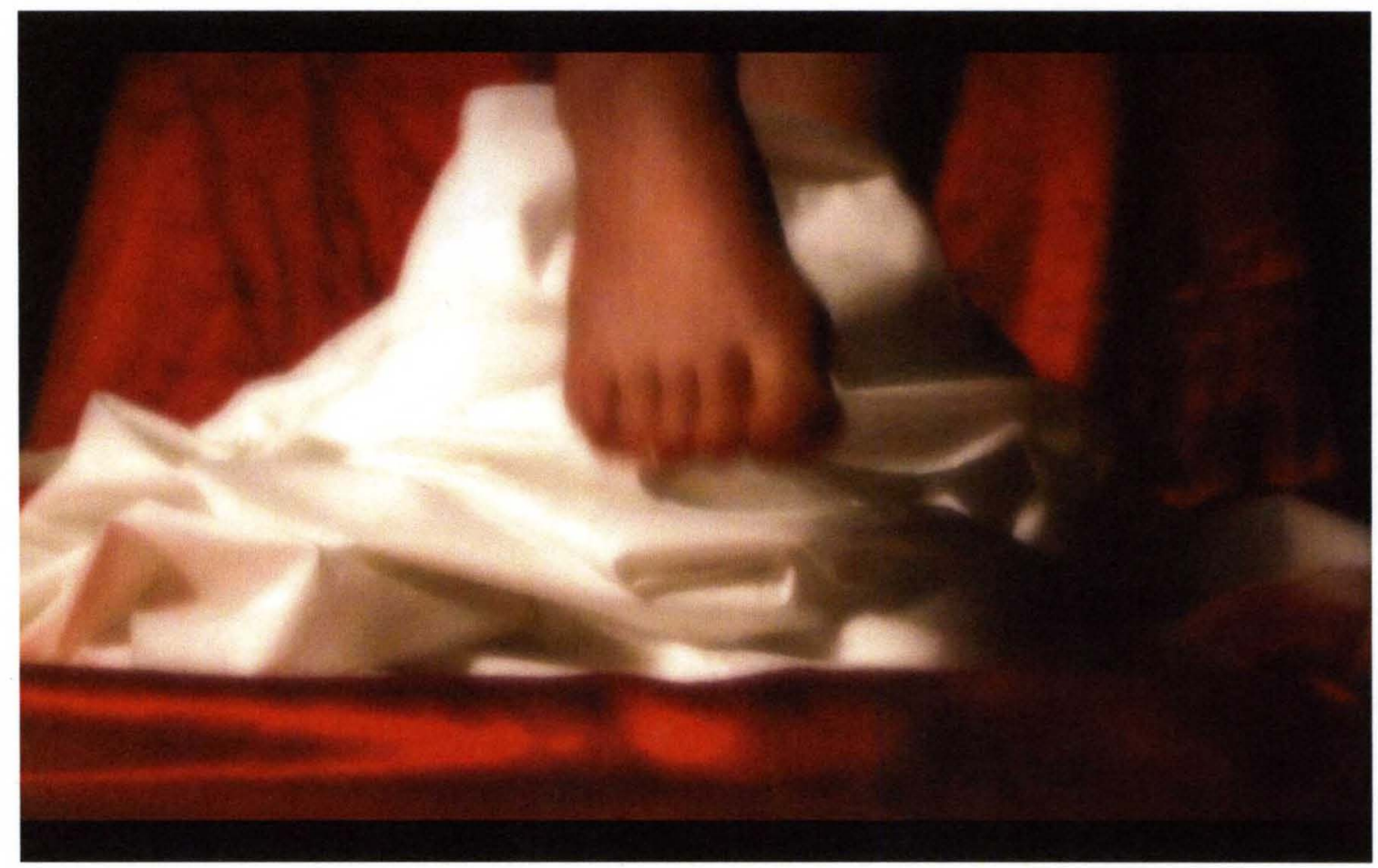

Again at the film's closing, I complete the theme as the actress removes the mask staring directly at the camera. Similar to the mask she has worn throughout the piece, her face lacks expression. She might be suffering but she no longer needs the mask to guard her from the difficult lessons she had to learn through experience and chaos. The music is what gives the meaning to the unfolding of events. A slow, meditative musical texture carries us to the final fade to black. She no longer remains idealist but neither does she remain ignorant of the chaos of human experience. Removing the parody of her real face, she becomes fully human. 


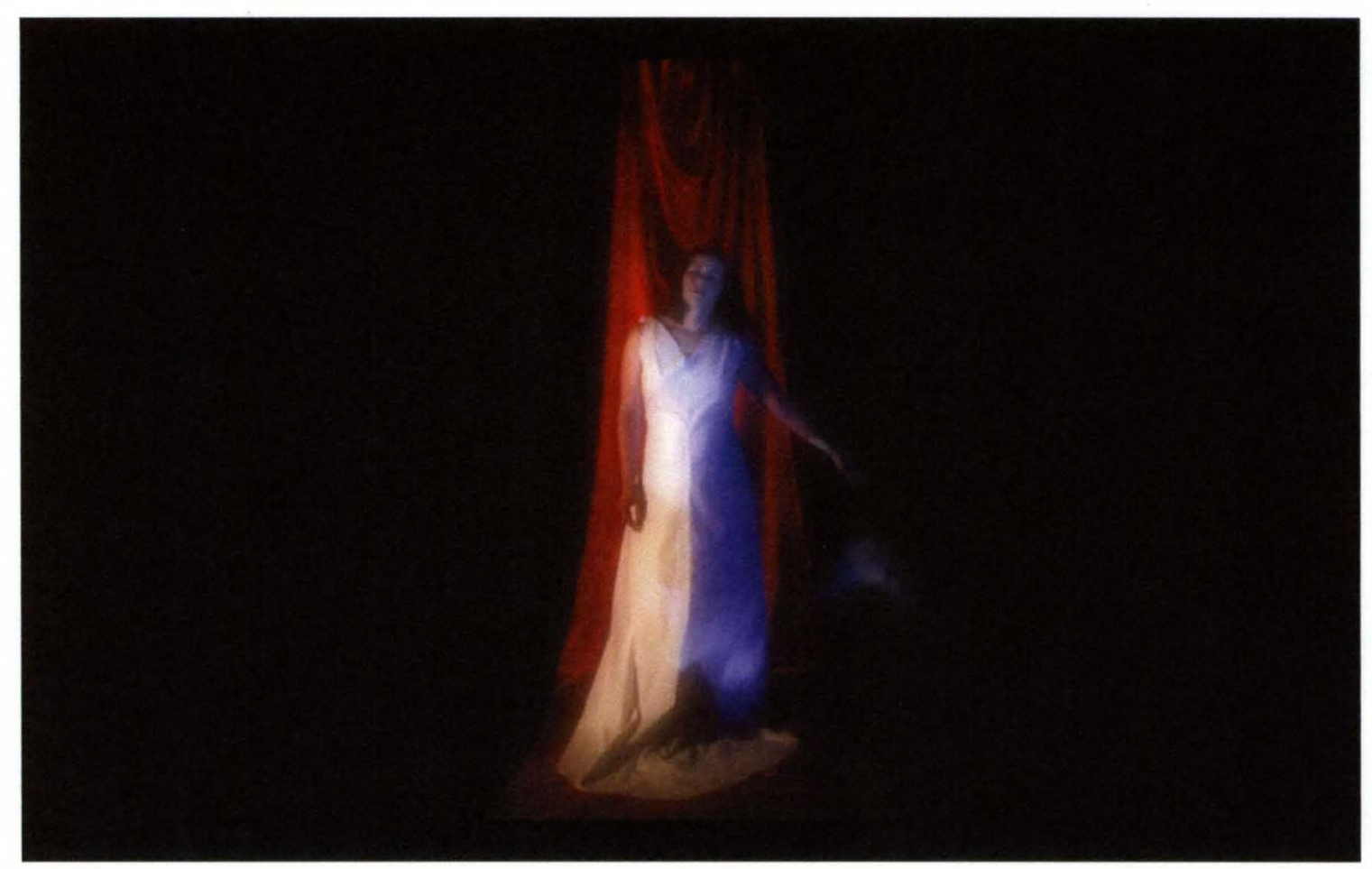




\section{EPILOGUE}

In creating this film, I employed a great deal of planning that I had to relinquish to the chaos of collaboration. I chose both actors and musicians as collaborators and all of them were people in whom I put a great deal of trust. In this way, I invited them into my adytum and gave some control away to allow for Nietzsche's Dionysian force. In art, Nietzsche described the Dionysian element of art as the chaos of improvisation; the musical force that causes us to lose our individual egos in the undulation of group chorus or dancing. The Apollonian force applies structure to art and we then see beauty in logic. As we have become more logical, symbolic and scientific as a nation, we come to see the chaos described by Nietzsche as "the spirit of music" as a primarily negative force that threatens the beauty of logic and structure. What results is an over-evaluation of literal elements, lyrics, and formal symbols. In film, this is manifested as the "linear" format, where a story unfolds in sequence and each plot point hinges on the previous. When we set ourselves up to view film this way, we behave the same way we do when we engage in formal debate. We look for plot holes and other elements that are logically amiss. Our willing suspension of disbelief has become extremely contingent and our society watches movies with the expectation that every visual event follows strict logic. In response, filmmakers provide love stories so ideal we feel lied to; or perhaps more realistic explosions, which cost more money, because that kind of documented destruction 
requires multiple takes. To me, modern cinema shows the imbalance of Western culture. I look to Eastern European filmmakers to break this trend.

In the works of Russia's Andrei Tarkovsky, the seamless movement between dream and consciousness comes as easily as the slow shots as the camera glides across the action of his long cuts. His subject matter is lonely and contemplative, often prolonged to the point of antagonizing a less patient audience. However, art and viewer form a relationship. When I regard the slow honest beauty of Tarkovsky's Nostalghia or The Mirror, modern American cinema as a whole feels like a one-night stand or a speeddating convention. This is not to say that there is no art in modern American cinema. There is art, but a director, like any politician, must dance around the boundaries of what is currently socially acceptable. Film is still a relatively young art form, emerging with technology in a time when women were extremely marginalized. Could the popularity, even the perceived authority of the linear format, mirror the minds of the moguls of this industry?

Biological anthropologist, Helen Fisher presented her work on the brain in love at a TED talk and discussed the differences in brain circuitry between men and women. Of women she says:

They tend to be web thinkers. Because the female parts of the brain are better connected, they tend to collect more pieces of data when they think, put them into more complex patterns, see more options and outcomes. They tend to be contextual, holistic thinkers, what I call web thinkers. Men tend to -- and these are averages -tend to get rid of what they regard as extraneous, focus on what they do, and move in a more step-by-step thinking pattern. They're both perfectly good ways of thinking. We need both of them to get ahead. (Fisher, 2006)

With The Adytum, I wanted to express the way I learn as a woman. Fisher's description of female thought as web-like or "holistic" struck a chord with me. When we see patterns in 
our lives, particularly those that cause negative emotions, it seems the most efficient and practical to look for the broken link, repair or delete it, then continue living. But this logical approach often leaves us in that same rut, conditioned to seeing the repetition of a pattern as simply a new, similar but different pattern that we should simply troubleshoot in the same way. This is not holistic thinking. For me, discovery and understanding comes with a kaleidoscopic revealing of themes. There is too much to see all at once and there is not one problem on which everything else is hinged. In the world, I find that nothing is extraneous, but everything is part of a larger concern. The goal of science is to help us predict the next line in a sequence, but the goal of prediction is control, whose ultimate goal is comfort. Ironically, there is a great comfort in relinquishing that control and all the associated labors in favor of simply allowing the world in all its complexity to reveal itself to you.

I communicated to my collaborators my desire for both documentary and contrived elements in this piece. As a director, I worked more like a mother and an organizer, developing the performances of each of my beloved friends based on what I knew of them individually. Occasionally I filmed them candidly without their specific knowledge that I wasn't just setting up. Other times I asked for something more acted. In every instance, I simply tried to create a situation that would be comfortable for experimentation and improvisation. I found that working from large themes and without giving the actors a linear script made me even more open to everyone's suggestions. Although the story was mine, I truly felt it was anyone's story, and anything I envisioned was easily influenced by the genuineness of what I could get from my collaborators naturally. Occasionally the faces of actors are revealed when the two-dimensional masks 
facing left or right, need to face the opposite direction. These accidents are welcomed as small tokens of vulnerability to the viewer, with whom we tried to negotiate communion. The process, with all its genuine awkwardness and discovery is evident in the product.

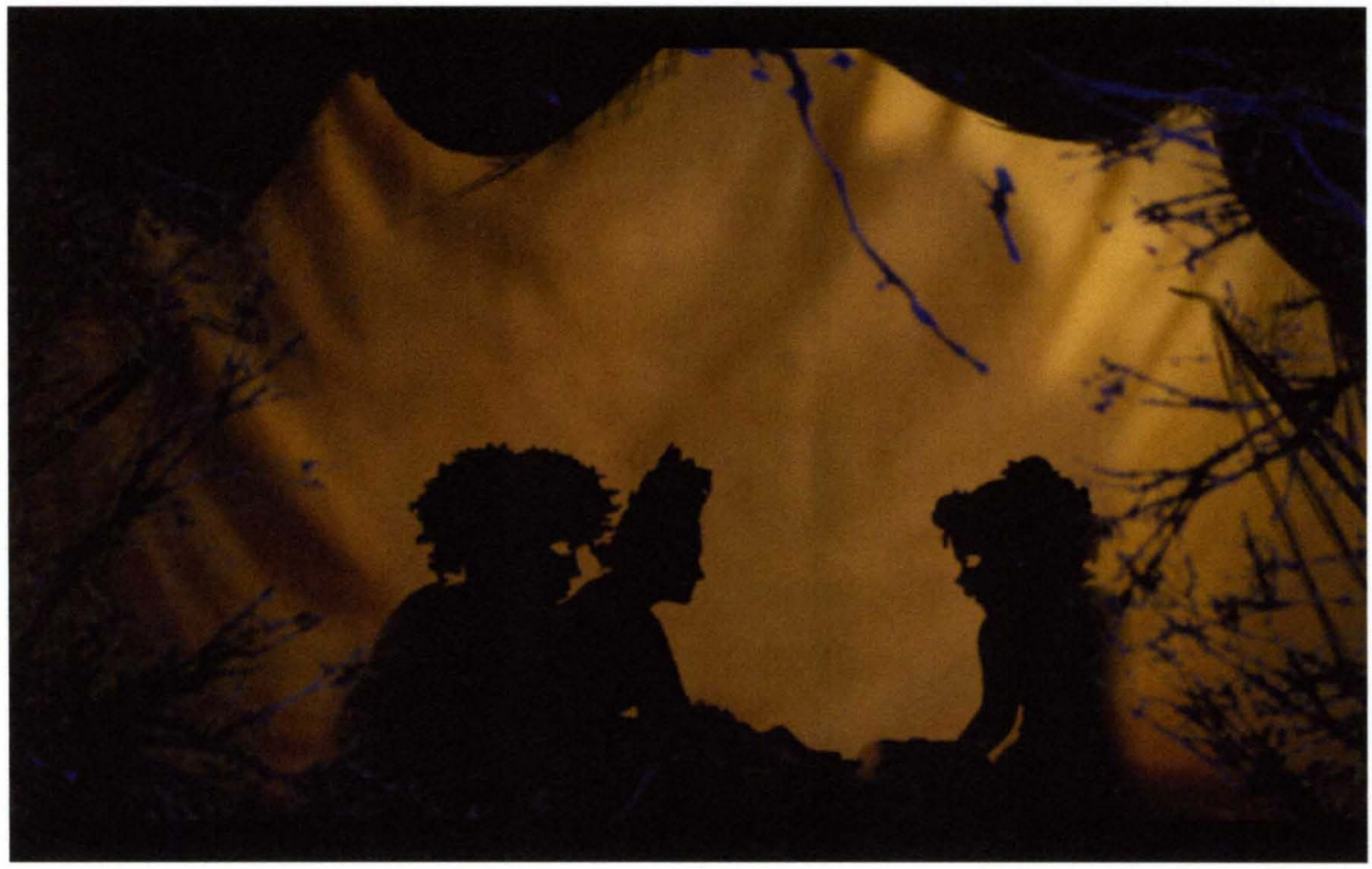

It is because of the era of science that the adytum of technology has opened its walls to me. I feel a profound respect for the inventors and manufacturers of tools I have used in creating this film as well as my fellow artists. Although we are all humans, subject to delusions of wisdom, we are united in our desire to make sense of our world. By science or by myth, we continue walking forward to mysterious silhouettes of the past as they dance on the walls; the seductive shapes of the future. 


\section{REFERENCES}

Belting, Hans. 1994. Likeness and presence: a history of the image before the era of art. Chicago: University of Chicago Press.

Bergland, Richard. 1985. The fabric of mind. Ringwood, Vic., Australia: Penguin Books.

Bullough, Vern L., and James A. Brundage. 1982. Sexual practices \& the medieval church. Buffalo, N.Y .: Prometheus Books.

Edwards, Betty, and Betty Edwards. 1999. The new drawing on the right side of the brain. New York: Jeremy P. Tarcher/Putnam.

Fisher, Helen. "Why we love and cheat." ted.com. http://www.ted.com/talks/helen_fisher_tells_us_why_we_love_cheat.html (accessed March 14, 2012)

Joseph, R. 2001. "The Limbic System and the Soul: Evolution and the Neuroanatomy of Religious Experience". Zygon. 36 (1): 105-136. 
Jung, Carl Gustav. 1964. Psychological types; or, The psychology of individuation. [New York]: Pantheon Books.

Micklewright, Keith. 2005. Drawing: mastering the language of visual expression. New

La Rochefoucauld, François, J. W. Willis Bund, and J. Hain Friswell. 1888. Reflections; or, Sentences and moral maxims. London: S. Low, Marston, Searle \& Rivington. York: Harry N. Abrams.

Monaco, James. 2009. How to read a film: Movies, media, and beyond: Art, technology, language, history, theory. New York: Oxford University Press.

Nietzsche, Friedrich Wilhelm, and Raymond Geuss and Ronald Speirs. 1999. The Birth of Tragedy. (Cambridgeshire): Cambridge University Press.

Nietzsche, Friedrich Wilhelm and Walter Arnold Kaufmann. 1974. The Gay Science; With a Prelude in Rhymes and an Appendix of Songs. (New York): Random House.

Nietzsche, Friedrich Wilhelm, Friedrich Wilhelm Nietzsche, Walter Arnold Kaufmann, and R. J. Hollingdale. 1989. On the genealogy of morals. New York: Vintage Books. 


\section{CURRICULUM VITAE:}

\section{LEXI BASS}

120 N. CLAY ST. APT. 202 | LOUISVILLE, KY 40202 | 502.821.3346 | lexibass@gmail.com

EDUCATION:

May 2004

BA in Arts Administration

Concentration in Theatre and Art

University of Kentucky

Jan. 2008

BFA Coursework in Communication Arts and Design Program

Hite Art Insitute

University of Louisville

Aug. 2009

MA Coursework in Fine Arts Graduate Program

Concentration in Video

Hite Art Institute

University of Louisville

AWARDS:

2012 Alice Eaves Barns Award

2012 Outstanding Graduate in Fine Arts Award

2012 Dean's Citation Award

\section{EXHIBITIONS:}

April 6, 2012 - May 2012

Hite Art Institute, University of Louisville

$\circ$ Artist - The Adytum (MA Thesis Exhibition, The Cressman Center for Visual Art)

Dec. 8, 2011

University of Louisville Ekstrom Library (Permanent Exhibition)

o Artist - Banned Books Project (Group Photography Show) 
October 18, 2011

4th Annual KY Short Film and Video Showcase, 21c Museum (Juried Screening)

o Composer/Producer - Chakra Study I (Music and Video)

Aug. 5-7, 2011

48 Hour Film Project - Screened at Village 8 Theatres, Louisville, KY on August 11, 2011

- Writer/Director/Sound Editor - Lock \& Key (Narrative Film)

$2010-2011$

University of Louisville School of Music

- Video Artist - Strangers (Collaboration with Composer, Jonathan D. Carter)

- Performer - "CliX" Louisville Laptop Orchestra (c.2007 Ge Wang \& Rebecca Siebrink)

o Composer/Performer - Literacy (Group Improv with Live Video Projection)

o Composer/Producer - Chakra Study I (Music and Video)

- Video and Fabric Artist - Shaman's Voice (Collaboration with Composer, Adriana

Guzman)

o Composer/Performer - Dr. Sinewave vs. Bluetooth the Vampire (Collaboration with Composer, Steven J. Crane)

Apr. 24, 2008

ART390 Student Short Film Exhibition, Floyd Theatre, University of Louisville

O Writer/Director - The Subtle Art of Homemaking (Short Film)

$\circ$ Director - Cholera and the Plague (Short Film)

\section{EDUCATIONAL EMPLOYMENT:}

Aug. 2011 - Present:

Hite Art Institute, University of Louisville

o Graduate Teaching Assistant - Instructor for ART101 Foundations 2D Design and Drawing

Mar. 2008 - May 2011

REACH Digital Media Suite, University of Louisville

o Graduate Service Assistant

Supervised and maintained the Digital Media Suite; Trained and Managed Media

Tutors; Tutor Payroll; Created implemented and enforced center policy;

Reported/analyzed usage data and statistics; Contributed data and planning at monthly meetings; Organized and promoted events; Archived student video projects for the Delphi Center.

o Media Tutor

Aided students with coursework in audio, video and graphic presentations, esp.

Final Cut Pro, Logic Pro, Soundtrack Pro, iMovie, and Adobe Creative Suite 5. 
Jul. 2010

Governor's School for the Arts, Lexington, KY

O Instructor

Prepared and lead a creative audio workshop for high school students.

Aug 2009 - May 2010

Hite Art Institute, University of Louisville

o Photo Lab Monitor

Prepared Darkroom Chemistry; Maintained organization/cleanliness 